\title{
The post-embryonic development of Remipedia (Crustacea)- additional results and new insights
}

\author{
Stefan Koenemann • Jørgen Olesen • Frederike Alwes • \\ Thomas M. Iliffe • Mario Hoenemann • Petra Ungerer • \\ Carsten Wolff • Gerhard Scholtz
}

Published online: 31 March 2009

(C) Springer-Verlag 2009

\section{Erratum to: Dev Genes Evol (2009) 219:131-145 \\ DOI 10.1007/s00427-009-0273-0}

Unfortunately the original publication contained errors.

All numerical values that specify larval size ranges in $\mu \mathrm{m}$ are to be multiplied by 10 (e.g., $1660 \mu \mathrm{m}$ instead of $166 \mu \mathrm{m})$.

The online version of the original article can be found at http://dx.doi. org/10.1007/s00427-009-0273-0.

S. Koenemann $\cdot$ M. Hoenemann

Institute for Animal Ecology and Cell Biology,

University of Veterinary Medicine Hannover,

Bünteweg $17 \mathrm{~d}$,

30559 Hannover, Germany

J. Olesen

Natural History Museum of Denmark, Copenhagen University,

Universitetsparken 15 ,

2100 Copenhagen, Denmark

F. Alwes $\cdot$ P. Ungerer $\cdot$ C. Wolff $\cdot$ G. Scholtz $(\bowtie)$

Institut für Biologie/Vergleichende Zoologie,

Humboldt-Universität zu Berlin,

Philippstraße 13,

10115 Berlin, Germany

e-mail: gerhard.scholtz@rz.hu-berlin.de

T. M. Iliffe

Department of Marine Biology,

Texas A\&M University at Galveston,

Galveston, TX 77553-1675, USA 